\title{
Using public procurement to implement environmental policy: an empirical analysis
}

\author{
Sofia Lundberg • Per-Olov Marklund • \\ Elon Strömbäck • David Sundström
}

Received: 21 August 2014/Accepted: 12 January 2015/Published online: 31 January 2015

(C) The Author(s) 2015. This article is published with open access at Springerlink.com

\begin{abstract}
Politicians expect green public procurement (GPP) to serve as an environmental policy instrument. However, in order for GPP to work as an effective policy instrument, it is important to take into consideration potential suppliers' decisions to participate in the procurement process, the total number of bidders, and the screening of bidders with respect to mandatory green criteria. The aim of this paper is to empirically study GPP in this respect. The analysis presented here is based on data from Swedish cleaning service procurements that are unique in that they contain very detailed information on various environmental standards set by the contracting authorities. We find at best only a weak effect on supplier behavior, and this suggests that the use of GPP in this situation does not live up to its political expectations.
\end{abstract}

Keywords Auctions - Compliance cost · Degree of competition · Endogenous entry $\cdot$ Objective effectiveness

JEL codes $\mathrm{D} 44 \cdot \mathrm{H} 57 \cdot \mathrm{Q} 01 \cdot \mathrm{Q} 28$

Financial support from the Swedish Research Council and the Umeå University Young Researcher Award is gratefully acknowledged.

S. Lundberg · E. Strömbäck · D. Sundström $(\bowtie)$

The Department of Economics at Umeå University, 90187 Umeå, Sweden e-mail: david.sundstrom@umu.se

S. Lundberg

e-mail: sofia.lundberg@umu.se

E. Strömbäck

e-mail: elon.stromback@umu.se

P.-O. Marklund

The Centre for Regional Science at Umeå University (CERUM) and the Centre for Environmental and Resource Economics (CERE), 90187 Umeå, Sweden

e-mail: per-olov.marklund@umu.se 


\section{Introduction}

Green public procurement (GPP) means that authorities stipulate and consider environmental criteria when public contracts are allocated to private suppliers and is becoming an established approach to pursue environmental policy in many parts of the world (Testa et al. 2012). The incentive to use GPP is based on the fact that in many countries public sector spending amounts to a significant part of the economy, and that this purchasing power can be used to influence production and consumption to achieve desired reductions on environmental impact. For example, authorities within the European Union (EU) annually spend on average 16 percent of the GDP on the procurement of goods, services, and works (European Commission 2008). The EU and its member states are very clear in their ambitions to use GPP as an environmental policy instrument (Tukker et al. 2008), and similar initiatives can be found in the US (Fischer 2010).

Despite the intended results, little is known about whether and how the supply side of the market-potential private suppliers-reacts to these ambitions. This paper seeks to fill this knowledge gap by providing an empirical analysis of how GPP affects potential suppliers' decisions to participate in public procurements. From the theoretical literature, it is known that the function of GPP as a policy instrument and its ability to fulfill - or to even contribute to-the achievement of environmental objectives is conditioned on the market response to the GPP procedures (Marron 1997; Lundberg and Marklund 2013a). In practice, participation is optional and is contingent on potential suppliers' expected pay-off from entering into GPP schemes (e.g., Samuelson 1985; Levin and Smith 1994; Li and Zheng 2009). The feature of optionality distinguishes GPP from more traditional environmental policy instruments such as emissions taxes.

More specifically, GPP means that authorities (e.g., a government authority, a public county hospital, or a municipality) in addition to quality criteria stipulate and consider environmental criteria when public contracts for public goods, services, or works are allocated to private suppliers. ${ }^{1}$ The environmental criteria can be associated with the intrinsic qualities of the contract as well as with the production process itself. In the procurements studied here, competitive sealed bidding is used to allocate the contracts and the selection of supplier is based on both environmental concerns and price. The GPP process includes a screening of the bids against mandatory green criteria, and only those bids that pass the screening qualify for the next step in which a winner of the contract is designated.

Theoretically, GPP as an environmental policy can work as a substitution policy (Marron 1997), a transformation policy (Lundberg and Marklund 2013a), or a combination of the two. In the first case, the purchasing authority substitutes a "brown" (conventional) product to a less environmentally harmful (green) alternative. The intention of a transformation policy is to encourage potential suppliers to stop producing for the conventional market and to invest in less

\footnotetext{
1 The European Commission defines GPP as a procurement situation in which “... public authorities seek to procure goods, services and works with a reduced environmental impact throughout their life-cycle compared to goods, services and works with the same primary function that would otherwise be procured." See http://ec.europa.eu/environment/gpp/versus_en.htm.
} 
environmentally harmful technologies and to produce instead for the green market. Both types of policy can have an effect on potential suppliers' decisions to enter into such agreements and to participate in specific procurements. This is of interest for at least two reasons. First, competition is important because it is a determinant of price. Simply put, the more the bidders are, the lower the price the authority will have to pay. Second, who participates and how many participate in such arrangements are important for the overall environmental pressure (Marron 1997, Lundberg and Marklund 2013a). From an environmental policy point of view, it is important that producers in the conventional market find it profitable to adapt to the green criteria and to invest in less environmentally damaging technologies. If procurements with environmental concerns only attract green suppliers, conventional suppliers will continue to produce brown.

According to Li and Geiser (2005), GPP can generate or enlarge the market for green products if public authorities are significant buyers. ${ }^{2}$ According to Marron (1997), however, this is not a sufficient condition for GPP to reduce environmental pressure and it can actually have the opposite effect. Through relative price changes, a substitution policy can lead to private consumers substituting green products for conventional products, and the public sector's environmental policy strategy can thus have a counter-productive substitution effect among private consumers. The net environmental impact is determined by how price-sensitive producers and consumers are. To assess the market reaction to GPP policies, it is thus essential to explore the firm-level decision to participate in the GPP process-as well as the aggregate number of bidders - and to relate this to procurements (contracts) with various green criteria.

From an environmental policy point of view, it is important that the specifications of environmental criteria are transparent and adequate with respect to specific environmental objectives. The misunderstanding of criteria by potential suppliers is associated with a risk of them deciding not to submit a bid or of them undertaking non-optimal green investments, and this potential problem is the motivation for analyzing the relationship between the GPP design and the qualification process.

Although GPP appears to be a well-established environmental policy instrument, it is not well studied in the academic literature and, as pointed out by Testa et al. (2012), this represents a relatively new area of research. There are studies that describe national GPP initiatives (e.g., Swanson et al. 2005; Bolton 2008; Geng and Doberstein 2008; Ho et al. 2010; Arvidsson and Stage 2012), provide guidelines (e.g., Parika-Alhola 2008; Tarantini et al. 2011), or study GPP uptake (Walker and Brammer 2009; Palmujoki et al. 2010; Testa et al. 2012), but none of these studies have provided a theoretical or empirical understanding of how GPP works as an environmental policy instrument.

Marron (1997) and Lundberg and Marklund (2013a, b) appear to be exceptions to the lack of research on the role of GPP in environmental policy. In short, these theoretical studies have identified shortcomings of GPP in terms of environmental policy and its potential to lead to reduced environmental impact. The current paper presented here adds to these previous studies by providing an empirical analysis of

\footnotetext{
$\overline{2}$ This finding is empirical and based on interviews.
} 
GPP as an environmental policy instrument. Based on a unique and rich dataset comprising procurements organized by Swedish authorities, it studies the effect of GPP on potential suppliers' decisions of whether or not to participate in the procurement process, the degree of competition, and the likelihood of a bid being disqualified.

The data were extracted from Swedish authorities' procurements of internal regular cleaning services from the years 2009 and 2010. For the 337 procurements, we have information about the type of authority, the procurement design, the object or facility to be cleaned, the contract and local market characteristics, all submitted bids, and whether or not a bid met all of the mandatory qualification criteria. The data also provide rich descriptions of the green criteria that are stipulated in each of the procurements. In total, we can identify 28 different green criteria. Because several of them are simply different ways of describing the same environmental dimension, the criteria are categorized into six different green variables. The data also describe the environmental dimension that the criteria aim to influence, such as environmental management systems, vehicles, and the use of chemicals, as well as other quality demands within the procurement.

Internal regular cleaning service contracts provide a good testing ground for studying GPP for several reasons. Internal regular cleaning services are relatively easy to contract and such services do not usually differ significantly in expected quality. This facilitates the identification of the effects that different green criteria have on participation. Further, the EU identifies cleaning products and services to be suitable for implementing GPP as it is seen to have scope for environmental improvement and potential impact on suppliers. ${ }^{3}$

The Swedish procurement rules and green procurement ambitions follow the EU procurement directives (2004/17/EC and 2004/18/EC) and the worldwide trend of increased use of GPP. Our research question is thus of potential interest for all EU member states as well as countries outside the EU that are using or are considering using public purchasing as a means to pursue environmental policy.

Our main finding is that the design of GPP, i.e., the different categories of green criteria, has only limited impact on the suppliers' decisions to participate in the process and on the aggregate number of bids. This applies regardless of whether the suppliers are small or large. The qualification process further reveals that some green criteria are associated with increased complexity as indicated by the reduced probability of a bid becoming qualified when environmental management systems or the regulation of chemical use is the criterion. Therefore, we find no general support for the political expectations of GPP as an environmental policy instrument.

The rest of this paper is organized as follows. In Sect. 2, we describe GPP. Section 3 formalizes the notions of entry and qualification and discusses these concepts in light of GPP. In Sect. 4, a descriptive presentation of the data is provided. Section 5 provides the empirical specifications and results, and Sect. 6 provides the conclusions of the study.

\footnotetext{
${ }^{3}$ http://ec.europa.eu/environment/gpp/gpp_criteria_en.htm.
} 


\section{Green public procurement}

In public procurement, it is quite common that contracts are allocated based on competitive sealed bidding. This is certainly the case in the procurements studied in the current paper, and we assess public procurement as defined by the EU procurement directives as: “...the measures implemented by a contracting authority with the aim of awarding a contract or concluding a framework agreement regarding products, services, or works" (Article 13). GPP is specifically defined as a situation in which contracting authorities take environmental considerations into account when buying products, services, or works (European Commission 2008). ${ }^{4} \mathrm{~A}$ contracting authority is a public body that is subject to the procurement regulations and is the buyer of the good, service, or works.

Following the World Trade Organization's Government Procurement Agreement and EU procurement directives, competitive sealed bidding is generally used when allocating public contracts. The procurement auction is initiated by publicly announcing the call for tender. Amongst other things, the announcement specifies the characteristics of the product to be procured as well as the contract conditions. The call for tenders also includes technical specifications, green and other quality criteria, and the principles for bid evaluation. A procurement auction can include one or several lots (one contract per lot), and bidding is simultaneous but independent over lots. That is, separate sealed bids are submitted on all or a subset of the lots included in the same procurement. Each potential supplier is allowed to submit one bid per lot, and contracts are assigned by lot (onwards contract).

Green criteria and other quality criteria can either be mandatory or optional. If only price and mandatory qualification and exclusion criteria are used as the allocation principle, the selection of the supplier is said to be based on the lowest price. On the other hand, if green and quality criteria take the form of optional award criteria and are accounted for in a scoring rule, ${ }^{5}$ the allocation of contracts is based on the most economically advantageous tender (MEAT). ${ }^{6}$ This gives the procurement the character of a multidimensional auction (e.g., Che 1993). The use of MEAT can be combined with mandatory criteria, and this is often the case in practice.

The bid evaluation process can be characterized by a two-step procedure consisting of a qualification phase followed by a bid evaluation phase. ${ }^{7}$ In the first step, each bidder is evaluated against a set of mandatory exclusion and qualification

\footnotetext{
${ }^{4}$ Note that this definition does not include auctions of nature conservation contracts, e.g., LataczLohmann and Van der Hamsvoort (1997), Stoneham et al. (2003).

5 See, e.g., Dini et al. (2006), Asker and Cantillon (2008, 2010), Lundberg and Marklund (2011) and Bergman and Lundberg (2013).

6 Also known as economically most advantageous tender, EMAT.

7 The two-step evaluation procedure is, from the perspective of potential bidders, a simultaneous process. A submitted bid includes prices, and the outcome of the qualification phase is made public at the same time as the outcome of the bid evaluation phase. This is somewhat different from, e.g. Texas Department of Transportation highway mowing auctions where the outcome of the qualification phase is known to the bidders prior to them submitting their price bids (see Li and Zheng 2009).
} 
criteria. ${ }^{8}$ Bidders that fulfill the requirements qualify for the second and final step in which bids are evaluated and a supplier is selected and assigned the contract.

Although the procurement process is regulated by law, implementation is decentralized in the sense that it leaves the contracting authority a great deal of freedom in exactly how to design the bid evaluation process and what environmental qualification and award criteria to consider. The criteria must, however, be linked to the subject matter of the contract and must comply with the general principles stipulated in the EU Directives (2004/17/EC and 2004/18/EC). The principles, which aim to promote an effective EU-wide and cross-border competition for public contracts and to prevent corruption, include equal treatment, transparency, non-discrimination, proportionality, and mutual recognition. To maximize business opportunities for companies within the EU internal market, all procurements with a total contract value exceeding a predetermined threshold must be advertised in the official database, Tenders Electronic Daily. The threshold value for internal cleaning services is 414,000 EUR. ${ }^{9}$

The EU Directives allow contracting authorities to define what a product is made of and how it is made in the technical specification of the procurement announcement. Potential suppliers may, therefore, have to change their production technology or the product itself to comply with the mandatory green criteria. Irrespective of the criteria addressing the production process or the product, the green criteria may target the use of resources or the negative effects of emissions (see Lundberg and Marklund 2013b). The use of GPP can specifically address things such as environmental management systems, references proving sustainability, certificates, standards, biodiversity, emissions into the air and water, energy and water consumption, chemical consumption, and waste generation (European Commission 2011).

When implementing GPP, there is an element of discretion and potential suppliers who do not meet the required environmental or quality standards can avoid the cost of adjusting to the criteria by not participating in the procurement process. When seeking to reduce emissions, GPP is, therefore, potentially weaker than taxes, tradable permits, subsidies, and standards, although any form of environmental regulation can lead to entry barriers (see, e.g., Heyes 2009 for a survey). Consequently, understanding the functioning of GPP as an environmental policy instrument in terms of objective effectiveness demands insights into how GPP affects potential suppliers' decisions to participate as well as the probability that a bidder will meet the mandatory criteria. For instance, the cost to adapt to environmental criteria may differ between potential suppliers depending on whether they have already made environmental investments or not, i.e., there may be systematic a priori cost asymmetries in adapting to the criteria. GPP policies might, therefore, give "greener" suppliers competitive advantages that induce them to

\footnotetext{
${ }^{8}$ Exclusion criteria deal with circumstances such as bankruptcy, serious misconduct, unpaid taxes, or social security contributions that normally prevent contracting authorities from carrying out any business with firms. For instance, companies that repeatedly breach environmental laws can be excluded on the grounds of grave professional misconduct (2004/17/EC and 2004/18/EC).

9 http://ec.europa.eu/internal_market/publicprocurement/rules/current/index_en.htm.
} 
participate to a greater extent. The empirical analysis presented here provides insights on these issues.

\section{Supplier response to GPP}

The general aim of this paper is to empirically study the market reaction to GPP, and a crucial aspect in this context is the individual potential supplier's decision on whether to participate in the procurement process or not. This decision is assumed to be contingent on the stringency of the environmental criteria in a given procurement relative to the technological status of the potential supplier. ${ }^{10}$ To have any environmental impact, the number of suppliers that actually adapt to these criteria also becomes crucial. A potential supplier who meets the environmental standards without any adjustments is said to be a producer of the environmentally preferable product. A potential supplier who to comply with the environmental demands needs to adjust its production process produces a competing product with more impact on the environment than is socially desirable but otherwise serving the same purpose.

Another aspect of GPP deals with the qualification process and the evaluation of bids. Transparent and adequately designed criteria that correspond well to the targeted environmental objectives will most likely facilitate participation and also benefit the environment. Non-transparent or inadequate criteria could potentially result in reduced participation or non-optimal green investments by potential suppliers. This section includes a simple theoretical framework addressing these aspects.

\subsection{The potential supplier's participation decision}

It is assumed that a potential supplier decides to participate in a given procurement process and submit a bid if the expected pay-off of doing so is non-negative. A bid typically consists of a price bid and a detailed description of how the bid complies with the green criteria that are specified in the call for tender. Preparing and submitting a bid is, therefore, associated with a bid preparation cost. Also, if a potential supplier does not comply with the criteria at the time when the call for tender is announced the supplier has to consider the cost of adapting to them. These costs affect the expected pay-off from participating (e.g., Li and Zheng 2009; Krasnokutskaya and Seim 2011), and they are here treated together as a participation cost $\left(k_{\mathrm{im}}\right)$.

It is also reasonable to regard potential suppliers as being heterogeneous in their ex ante environmental performance (e.g., green and conventional suppliers), and their costs for adapting to green criteria will differ (Lundberg and Marklund 2013b). That is, for a given procurement, $k_{i m}$ will differ across potential suppliers due to different adaption costs. The green criteria are (following practice) specified on the

\footnotetext{
${ }^{10}$ Environmental criteria henceforth include both mandatory qualification criteria and optional award criteria.
} 
procurement level $(\mathrm{m})$, and as such constant over the contracts auctioned in one and the same procurement.

Preparation and adaption costs are likely to increase with the number of green criteria, their stringency, and their complexity. It is, therefore, reasonable to regard the decision to participate in the procurement process as endogenously determined by the green criteria. ${ }^{11}$ The potential supplier's decision to participate can be said to be determined by the following condition:

$$
E\left(\pi_{i j m}\right)=\max _{b_{i j m}}\left(b_{i j m}-c_{i j m}\right) \operatorname{Pr}(\text { winning })-k_{i m} \geq 0
$$

which states that a potential supplier $i=1, \ldots, N$ will submit a bid, $b_{i j m}$, on contract $j=1, \ldots, J$ in procurement $m=1, \ldots, M$ if the expected pay-off from doing so, $E\left(\pi_{i j m}\right)$, is non-negative. The expected profit is also determined by the potential supplier's private production cost, $c_{i j m}$, and the likelihood of winning the contract. See, e.g., Milgrom (2004) for further details.

Consequently, the expected profit will vary across potential suppliers. It follows from Eq. (1) that potential supplier $i$ will submit a bid when the underlying continuous expected net profit function, $\pi_{i j m}^{*}$, is non-negative, i.e.,

$$
\pi_{i j m}^{*}=\mathrm{E}\left(\pi_{i j m}\right)=V\left(x_{i}, s_{j}, z_{m}\right) \geq 0
$$

where $V(\cdot)$ is a function that links the potential supplier's participation decision to its expected net profit. It includes a vector of supplier-specific variables, $x_{i}$, contract characteristics, $s_{j}$, and procurement characteristics, $z_{m}$.

The underlying expected net profit in Eq. (2) is not directly observed, but the binary outcome variable, $y_{i j m}$, is observed with $y_{i j m}=1$ if $\pi_{i j m}^{*}>0$. Hence, the participation decision rule is specified generally as follows:

$$
y_{i j m}=1 \quad \text { if } \pi_{i j m}^{*}=V\left(x_{i}, s_{j}, z_{m}\right) \geq 0
$$

That is, $y_{i j m}$ takes a value of one if potential supplier $i$ is observed to submit a bid on contract $j$ in procurement $m$ and is zero otherwise. ${ }^{12}$

In accordance with a transformation policy, a given procurement process contributes to reduced environmental impact when potential suppliers adapt to the green criteria specified in the call for tender and invest in environmentally friendlier production processes and products. If only potential suppliers that already comply with the criteria decide to participate in the procurement process, there will be no

\footnotetext{
11 See Samuelson (1985) and Levin and Smith (1994) for more reading on endogenous entry.

12 To be able to identify the underlying expected profit function in Eq. (2), through the potential supplier's observed decision to participate in the procurement process in Eq. (3), we assume that the participation decisions of bidder $i$ and $-i$ (where $i \neq-i$ ) are independent of each other. Independence is implied theoretically by the assumption of the independent and identically distributed (i.i.d.) cost parameters and the assumption that the bid strategy, $b_{i j m}=b\left(c_{i j m}\right)$, is strictly increasing in $c_{i j m}$ (e.g. Milgrom 2004). Then, for a given participation cost, $k_{i m}$, participation is independent across bidders and this is consistent with the single-agent model originally proposed by McFadden (1974).
} 
environmental impact as long as they do not displace conventional suppliers from the market.

\subsection{Number of bidders}

The aggregate of individual participation decisions described by Eq. (1) corresponds to the degree of competition, i.e., the number of actual bidders on each contract. Therefore, it is also relevant to study the relationship between GPP and the number of bidders. A potential supplier who has submitted a bid is defined as a bidder.

Following Lundberg et al. (2012), and assuming that the cost of adapting to green criteria increases at an increasing rate as the stringency of the criteria increases, the relation between the stringency of green criteria and the number of bidders is illustrated in Fig. 1.

For simplicity, we assume that all $N$ potential suppliers prior to the procurement process are conventional suppliers and that they have different production technologies. All of them contribute to emissions but to varying degrees. If the contracting authority stipulates green criteria corresponding to some environmental standard, $G P P_{m}^{0}$ (aiming for a specific environmental objective $\left(\gamma^{*}\right)$, e.g., reduced carbon emissions), it follows that $N-n^{0}$ potential suppliers will refrain from bidding. However, we can also assume that the contracting authority foresees this and, based on $n^{0}$ and the environmental objective $\gamma^{*}$, stipulates even tougher criteria $G P P_{m}^{1}>G P P_{m}^{0}$. Consequently, the tougher GPP level increases the required per

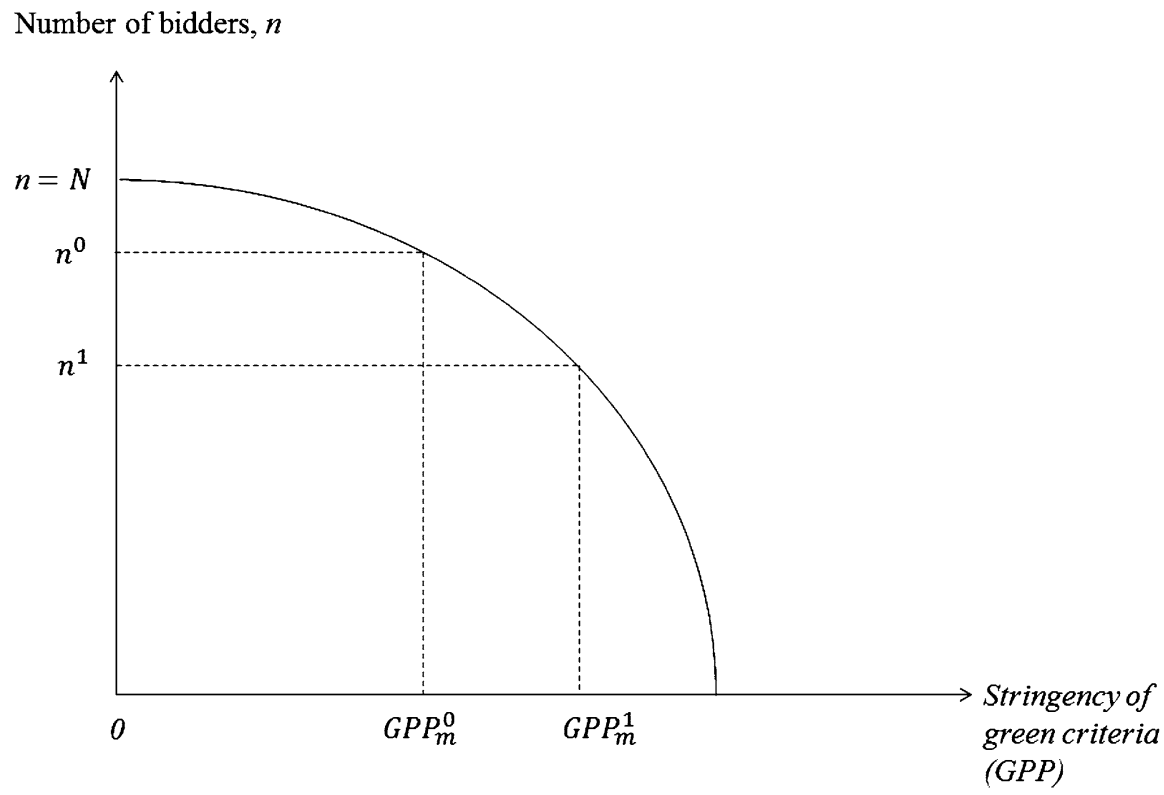

Fig. 1 The relationship between the stringency of green criteria and the number of actual bidders for a specific environmental objective $\gamma^{*}$ (see Lundberg et al. 2012) 
bidder adaption cost and $N-n^{1}$ bidders will drop out. Accordingly, participation decreases at an increasing rate as the criteria become more stringent. All things being equal, a procurement without green criteria would imply zero adaption cost and the number of bidders would be equal to the number of potential conventional suppliers. No environmental improvements will result from this particular procurement process and the environmental objective, $\gamma^{*}$, will not be achieved or even contributed to. Paradoxically, this is the same outcome as would occur under a scenario with green criteria and participation from only potential suppliers that prior to the procurement process already comply with the criteria (as long as they do not displace conventional suppliers), i.e., green suppliers. Here, we empirically study the relationship between the stringency of green criteria and the number of bidders at the contract level according to $n_{j m}=G\left(s_{j}, z_{m}\right)$.

\subsection{Screening and qualification}

When the bidding process is over, all bidders are screened against the mandatory criteria in a first step. Bidders that for some reason do not fulfill the mandatory criteria are disqualified. In a second step, the qualified bidders are evaluated with respect to the award criteria, including the price. ${ }^{13}$

From an environmental policy point of view, it is important that the contracting authority specifies transparent and adequate green criteria according to some predetermined environmental objective. ${ }^{14}$ Misinterpretation of criteria on behalf of potential suppliers is associated with a risk of them making the wrong participation decision, i.e., deciding to not participate instead of participating or vice versa. Also, once deciding to participate, there is a risk of them not undertaking the green investments in the manner desired by the contracting authority and, therefore, they will be disqualified. Unclear criteria not only violate the principle of transparency, but they also compromise the ability of GPP to have the desired environmental effect simply because the authority (the regulator) and bidders (the regulated) do not agree on the exact nature of the stipulated green criteria.

Formally, let $q_{i}$ in the interval $[q, \bar{q}]$ denote a value that reflects the outcome of screening bidder $i$ against the mandatory criteria. Following Wan and Beil (2009), bidder $i$ is assumed to be qualified if the value is weakly larger than a predetermined qualification threshold value as indexed by $q_{m}^{0}$, i.e., if $q_{i} \geq q_{m}^{0}$. Furthermore, with $q_{i}$ distributed according to $H(\cdot)$, the probability of bidder $i$ becoming qualified is expressed by

$$
\rho_{i m}=1-H\left(q_{m}^{0}\right)
$$

where $\rho_{i m}$ is strictly decreasing in $q_{m}^{0}$. Simply stated, all things equal, the more complex the criteria the less likely bidder $i$ is to qualify. The strictness of the qualification threshold can now be re-expressed as $q_{m}^{0}=q\left(\rho_{\text {im }}\right) \equiv H^{-1}\left(1-\rho_{i m}\right)$.

\footnotetext{
13 This approach is different from what is known in the literature as pre-qualification, which is a situation in which the screening occurs prior to the bidding (e.g. Wan and Beil 2009).

14 The criteria should reflect the preferences of the part of society the contracting authority represents (see Lundberg and Marklund 2011).
} 
Furthermore, bidder $i$ 's underlying ability to qualify is denoted by $q_{i m}^{*}=$ $q_{i}-q_{m}^{0} \geq 0$ and is not directly observed in the data. Instead, the binary outcome variable of actually being qualified or not, $d_{i m}$, is observed with $d_{i m}=1$ if $q_{i m}^{*} \geq 0$. Hence, the selection rule is specified generally as follows:

$$
d_{i m}=1 \quad \text { if } q_{i m}^{*}=H\left(x_{i}, z_{m}\right) \geq 0
$$

where $H(\cdot)$ is a function of supplier-level characteristics, $x_{i}$, and procurement-level characteristics, $z_{m}$.

\section{The data}

Our data consist of internal regular cleaning service procurements from the years 2009 and $2010 .{ }^{15}$ Internal regular cleaning service contracts are chosen because they provide a good testing ground for GPP. It is a relatively easy service to contract for, it is not associated with severe capacity constraints, and it does not differ much in quality prior to the procurement process. This facilitates identification of the effects of different green criteria on the potential suppliers' decisions of whether to participate in the procurement process. Another reason for using data from internal regular cleaning service procurements is that the EU has identified cleaning products and services as one of the 20 prioritized sectors. These sectors were, among other things, selected based on their scope for environmental improvement and impact on suppliers. ${ }^{16}$

Information about the procurements was obtained from a national database in which call-for-tender notices are advertised in Sweden. ${ }^{17}$ In addition to the basic information about the procurement, information was extracted from procurement documents such as the call for tender itself, the technical specification, the tender compilation, and records of the procurement decision. The technical specifications are very detailed about how, with what materials, and how often the facilities are to be cleaned. Information about the potential suppliers and local market characteristics is collected from Statistics Sweden (SCB).

The dataset consists of 337 procurement auctions comprising 722 contracts on which a total of 4,699 bids were placed. One contract can comprise one or several premises to be cleaned. We can identify 341 unique potential suppliers in the data (see footnote 26) and 153 of these are never disqualified.

\subsection{Procurement and market characteristics $\left(z_{m}\right)$}

Procurement and market characteristics, $z_{m}$, include a wide range of different characteristics, including green criteria as well as other criteria addressing quality aspects of the cleaning service and the production of the same. The criteria are

\footnotetext{
15 Three procurements in the dataset were carried out in late December 2008.

$16 \mathrm{http}: / /$ ec.europa.eu/environment/gpp/gpp_criteria_en.htm.

17 Visma Commerce AB. This is the largest such data base in Sweden and it covers approximately 90 percent of all procurements.
} 
divided into qualification and award criteria and are constant over contracts auctioned in one and the same procurement. Of particular focus in this study are green criteria. Detailed information about these was collected from the call for tender, and 28 unique green criteria were identified. ${ }^{18}$ The number of different green criteria varies across procurements and ranging from no criteria to 17 criteria (see the left diagram in Fig. 2).

To reduce the dimensionality in the empirical analysis, we categorized the 28 observed green criteria into six main characteristics to be included in the procurement and market variables vector, $z_{m}$.

The variable Environmental management system (EMS) condenses information on criteria that are related to environmental measures that potential suppliers do not have to implement by law, i.e., having an environmental management system, obtaining environmental certificates, and fulfilling different ISO 14000 standards. $^{19}$ Eco labeling (ECO) is also voluntary and concerns ecological labeling of cleaning products (e.g., the EU Ecolabel or equivalent). Vehicle (VEH) includes criteria stipulating emission standards for cars (e.g., Euroclass, ${ }^{20}$ fuel specifics, eco driving, etc). Criteria that require the supplier to follow the Swedish Chemicals Agency B-list, ${ }^{21}$ the Swedish Environmental Code, the decree on Registration, Evaluation, Authorization, and Restriction of Chemicals (REACH), ${ }^{22}$ the Swedish Chemicals Agency Code of Statutes 2008, and similar regulations are classified as being chemical criteria (CHEM). At this point, all criteria but VEH are quite frequently being represented in the procurements. In only 10 percent of the procurements, the authority signals that it intends to monitor that the supplier delivers according to the environmental concerns stipulated in the contract (see Table 1). This criterion is defined as Eco monitoring (MON). Finally, other types of criteria, e.g., recommendations by the Swedish Environmental Management Council and allergy considerations, are included in the other eco demands (OTHER) category.

\footnotetext{
18 Descriptive statistics of the green criteria are given in "Appendix 1", Table 4.

19 According to the web page for ISO: "ISO 14001:2004 sets out the criteria for an environmental management system and can be certified to. It does not state requirements for environmental performance, but maps out a framework that a company or organization can follow to set up an effective environmental management system. It can be used by any organization regardless of its activity or sector. Using ISO 14001:2004 can provide assurance to company management and employees as well as external stakeholders that environmental impact is being measured and improved." http://www.iso.org/ iso/iso 14000 .

20 Within the EU, there are emission standards defining acceptable limits for exhaust emissions of different types of new vehicles (cars included) sold in the member states. These standards include emissions of nitrogen oxides (NOx), total hydrocarbon (THC), non-methane hydrocarbons (NMHC), carbon monoxide (CO), and particulate matter (PM). See the European Commission website: http://ec. europa.eu/environment/air/transport/road.htm.

21 See the Swedish Chemical Agency website: http://www.kemi.se/.

22 Regulation (EC) No 1907/2006 of the European Parliament and of the Council of 18 December 2006 concerning the Registration, Evaluation, Authorization and Restriction of Chemicals (REACH), establishing a European Chemicals Agency, amending Directive 1999/45/EC and repealing Council Regulation (EEC) No 793/93 and Commission Regulation (EC) No 1488/94 as well as Council Directive 76/769/EEC and Commission Directives 91/155/EEC, 93/67/EEC, 93/105/EC, and 2000/21/EC. http://ec. europa.eu/enterprise/sectors/chemicals/reach/index_en.htm.
} 

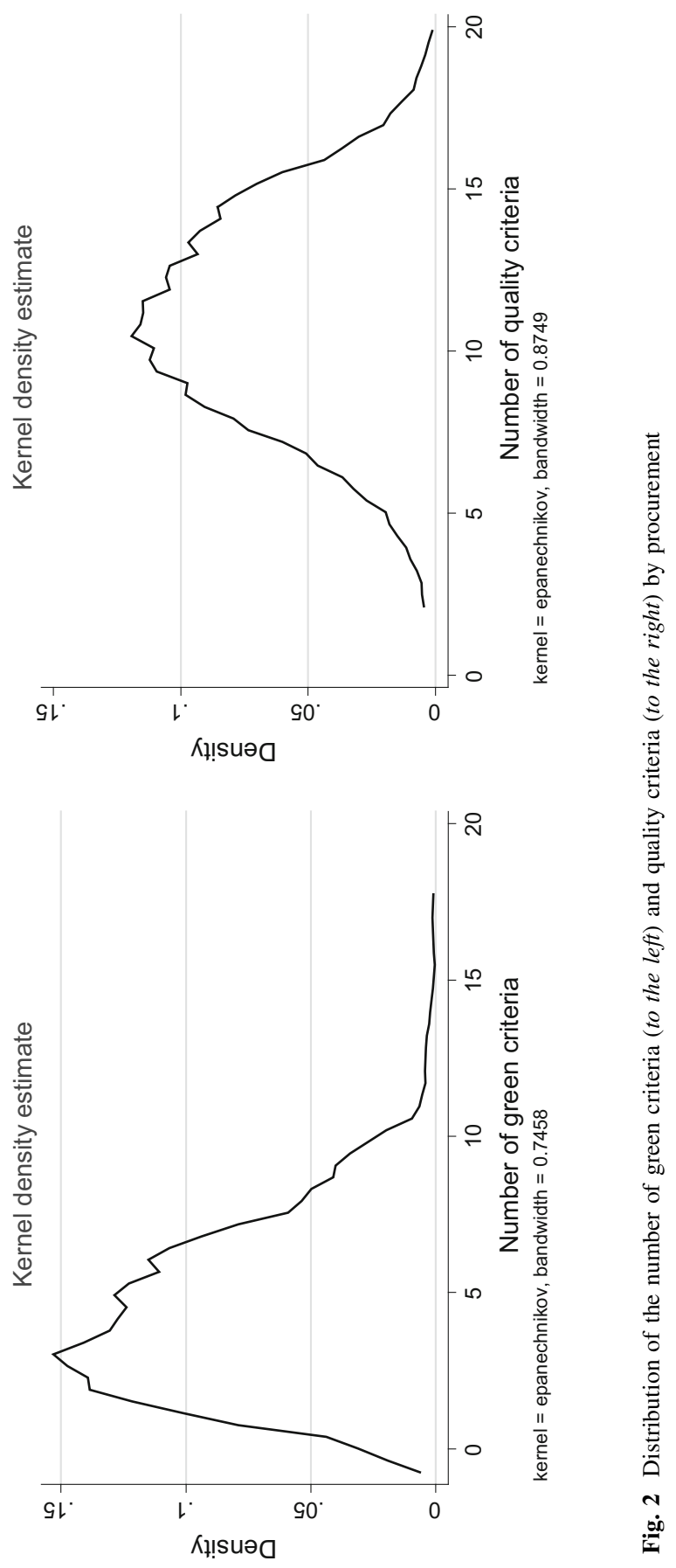
Table 1 Variables summarizing the green criteria identified in the call for tenders

\begin{tabular}{llllll}
\hline Green variables & Mean & Min. & Max. & Std. dev & Obs \\
\hline Environmental management system (EMS) & 0.61 & 0 & 1 & 0.49 & 337 \\
Eco labeling (ECO) & 0.62 & 0 & 1 & 0.49 & 337 \\
Vehicles (VEH) & 0.03 & 0 & 1 & 0.17 & 337 \\
Chemicals (CHEM) & 0.72 & 0 & 1 & 0.45 & 337 \\
Eco monitoring (MON) & 0.10 & 0 & 1 & 0.31 & 337 \\
Other eco demands (OTHER) & 0.48 & 0 & 1 & 0.50 & 337 \\
\hline
\end{tabular}

We can also identify 26 unique quality criteria that do not relate to environmental quality, e.g., those that relate to the performance of the cleaning service itself, the financial status of the potential supplier, tax certificates, employees' qualifications, union rights, etc. As illustrated in the diagram to the right in Fig. 2, the number of different quality criteria varies across procurements and ranging from 3 to 17 criteria. On average, the authorities stipulate more qualitative criteria (11.1) than green criteria (4.5). Again, to reduce the dimensionality in the empirical analysis, we categorize the 26 observed quality criteria into six main variables ${ }^{23}$ (see Table 2).

Financial status (FIN) relates to criteria with the goal of ensuring that the supplier's financial condition is solid (e.g., annual reports or information on turnover). It is also quite common that the authorities formulate criteria to ensure that the suppliers have relevant insurance, and these are included in the insurance (INS) variable. The experience (EXP) variable includes criteria demanding potential suppliers to prove them having relevant experience with similar assignments. Performance plan (PER) refers to criteria that demand the potential supplier to provide an implementation plan, i.e., a description of how the cleaning service contract will be carried out. Social criteria (SOC) include the criteria that the potential supplier needs to have collective labor agreements with the union, etc. Finally, staffing (STAF) is a variable that includes criteria describing the qualifications of the employees.

So far we have only discussed green criteria and quality criteria, but other procurement characteristics will also be controlled for in the empirical analysis and these are listed in Table 2. We have information on whether the contracting authority is a local government (municipal) or not (MUNI). As mentioned earlier, a contracting authority can award contracts based on either of two principles, lowest price or MEAT $(M E A T)$. In our data, both principles occur equally as frequently. The size of the procurement may also be of importance based on its attractiveness in terms of monetary value and economies of scales in potential suppliers' production. Procurement size is most likely positively correlated with the production cost, modeled as $c_{i j m}$ in Eq. (1), and we include two different size indicators, the number of contracts included in one and the same procurement (\#SUBC) and the area to be

\footnotetext{
23 Descriptive statistics of all the quality criteria listed in the call for tenders are given in "Appendix 1," Table 4 . The most frequently used quality criterion is the requirement of limited liability insurance, which is included in the variable insurance (see "Appendix 1," Table 4).
} 
Table 2 Descriptive statistics on procurement, contract, and supplier variables

\begin{tabular}{|c|c|c|c|c|c|}
\hline Variable & Mean & Min. & Max. & Std. Dev. & Obs. \\
\hline \multicolumn{6}{|l|}{ Procurement level } \\
\hline Financial status $(F I N)$ & 0.96 & 0 & 1 & 0.19 & 337 \\
\hline Insurance $(I N S)$ & 0.93 & 0 & 1 & 0.25 & 337 \\
\hline Experience $(E X P)$ & 0.91 & 0 & 1 & 0.29 & 337 \\
\hline Performance plan $(P E R)$ & 0.98 & 0 & 1 & 0.15 & 337 \\
\hline Social criteria $(S O C)$ & 0.33 & 0 & 1 & 0.47 & 337 \\
\hline Staffing $(S T A F)$ & 0.89 & 0 & 1 & 0.31 & 337 \\
\hline $\begin{array}{l}\text { Type of contracting authority, municipality } \\
(M U N I)\end{array}$ & 0.50 & 0 & 1 & 0.50 & 337 \\
\hline Award method (MEAT) & 0.50 & 0 & 1 & 0.50 & 337 \\
\hline Number of contracts per procurement (\#SUBC) & 2.21 & 1 & 51 & 4.26 & 337 \\
\hline Total area to be cleaned, square meters (\#SQMP) & $19,677.01$ & 40 & 884,000 & $65,156.68$ & 337 \\
\hline \multicolumn{6}{|l|}{ Contract level } \\
\hline \multicolumn{6}{|l|}{ Type of facility ${ }^{a}$} \\
\hline School & 0.30 & 0 & 1 & 0.46 & 722 \\
\hline Office & 0.52 & 0 & 1 & 0.50 & 722 \\
\hline Other & 0.46 & 0 & 1 & 0.50 & 722 \\
\hline Additional services index (SERVICE) & 2.39 & 0 & 4 & 1.20 & 722 \\
\hline Area to be cleaned, square meters (\#SQMC) & $9,196.90$ & 26.90 & 403,658 & $27,178.43$ & 722 \\
\hline \multicolumn{6}{|l|}{ Potential suppliers } \\
\hline $\begin{array}{l}\text { Headquarters is in the same labor market area } \\
\text { (LMA) as the delivery site }(H E A D Q)\end{array}$ & 0.71 & 0 & 1 & 0.45 & 30,000 \\
\hline Limited liability firms (corporations) (LTD) & 0.80 & 0 & 1 & 0.40 & 301 \\
\hline Class size (SCB definition) (SIZE) & 4.79 & 0 & 16 & 3.15 & 301 \\
\hline Number of potential bidders by region $\left(N_{j m}\right)$ & 14.27 & 2 & 174 & 23.58 & 56 \\
\hline Number of received bids per procurement $\left(n_{m}\right)$ & 7.11 & 1 & 37 & 4.70 & 337 \\
\hline Number of qualified bids $\left(n_{j m}\right)$ & 5.62 & 1 & 23 & 3.13 & 722 \\
\hline
\end{tabular}

a Note that one contract can include a multiple set of premises to be cleaned

cleaned in square meters (\#SQMP). Both measures are justified because a high total value on the procurement level can be explained by a single large contract as well as by many small contracts.

The average number of contracts within one and the same procurement is 2.21 and varies between 1 and 51. Also, the total area to be cleaned varies considerably and is on average approximately $20,000 \mathrm{~m}^{2}$.

\subsection{Contract characteristics $\left(s_{j}\right)$}

The contract characteristics, $s_{j}$, include variables that are unique for each contract, such as the type of premises to be cleaned (SCHOOL, OFFICE, OTHER) and its size measured in square meters (\#SQMC). Most of the contracts concern cleaning of schools $(30 \%)$ and offices $(52 \%)$. 
In addition to the regular cleaning service, the contracting authority sometimes demands optional services that require more resources and, therefore, might have an impact on the potential suppliers' decision to participate and, consequently, on the number of bids. For instance, special equipment is required for additional services such as window cleaning and floor cleaning, which occur in 55 and $74 \%$ of the contracts, respectively, in our dataset. Other additional services are periodic cleaning and the provision of consumables such as hygiene material. In the estimations, we measure additional service as an index (SERVICE) by counting the number of additional services included in each contract. As can be seen from Table 2, the number of additional services is on average 2.40 per contract. Finally, the areas to be cleaned vary considerably between contracts and are on average about $9,000 \mathrm{~m}^{2}$.

\subsection{Potential supplier-specific variables $\left(x_{j}\right)$ and the set of potential suppliers}

The vector $x_{j}$ includes variables on characteristics that are unique for each potential supplier. The first one is a dummy variable that takes a value of one if the potential suppliers have their headquarters located in the same labor market area (LMA), ${ }^{24,25}$ as the premises to be cleaned $(H E A D Q)$. This is the case for about $71 \%$ of the potential suppliers. The second variable is corporate form (LTD). This variable takes a value of one if the firm is a limited company, which $80 \%$ the potential suppliers are. Finally, firm size $(S I Z E)$ is measured by dividing the potential suppliers into 16 size classes with respect to the number of employees according to the definition of SCB. See Table 5 in "Appendix 1". The average potential supplier is a firm with 20-49 employees.

In the estimations, we also include different measures of competition. The first variable, $N_{j m}$, is the number of potential suppliers per LMA. A firm is defined as a potential supplier in a specific LMA if it is observed in our data as a bidder on at least one contract in that LMA (a similar approach can be found in Jofre-Bonet and Pesendorfer 2000, 2003). The average number of potential suppliers in a LMA is approximately 14 , see Table $2 .^{26}$

The second variable related to competition is the number of received bids, $n_{m}$, and is measured at the procurement level. As shown in Table 2, it varies between 1 and 37 with a mean of 7.11. Finally, the number of qualified bids per contract, $n_{j m}$, is 5.62 on average.

\footnotetext{
24 Jofre-Bonet and Pesendorfer (2000, 2003) estimate the suppliers' decisions of participation, i.e., their entry decisions, in a dynamic setting by taking so-called backlog into account.

25 The concept of the LMA is based on the observed commuting patterns of workers in Sweden. Different communities are tied to a particular LMA if they are highly intertwined by commuting services and thus form a homogeneous area of commerce (see SCB).

${ }^{26}$ It is not straightforward to define the set of potential suppliers; it may influence the results as a supplier can be interested in contracts outside the LMA in which the supplier is located. As a robustness check, we extend the set of potential suppliers to cover all distinct suppliers in the sample. This results in $N_{j m}=341$ potential suppliers for each contract and is discussed more below and in "Appendix 3." Note that the 341 potential suppliers are all the firms observed in our data, i.e., all firms that have submitted a bid in any Swedish public procurement for internal cleaning services in 2009 and 2010.
} 

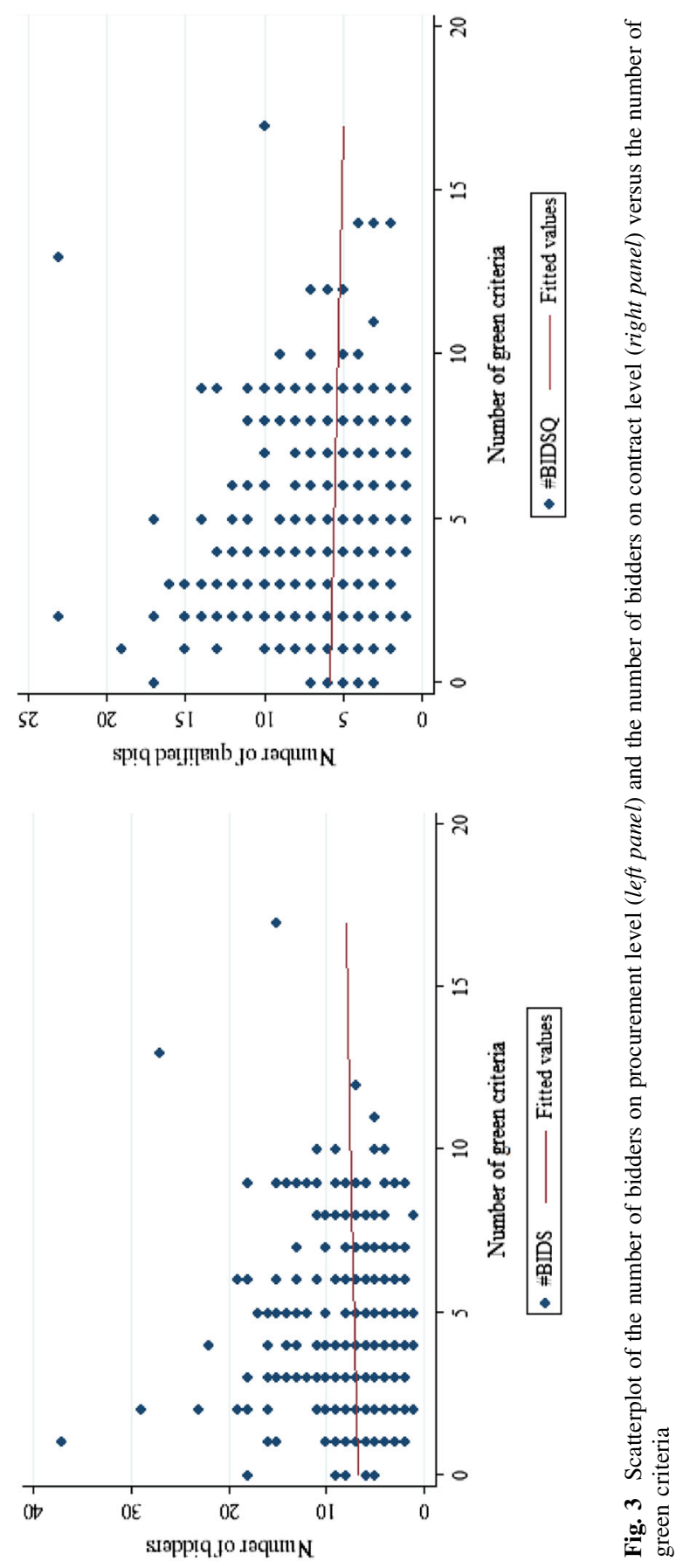
Figure 3 illustrates the correlation between the number of green criteria in one and the same procurement and the number of bidders (to the left) and the number of qualified bidders per contract (to the right).

It is not clear from Fig. 3 what effect to expect from GPP (as measured by the number of green criteria) on the number of bidders and the number of bids submitted by qualified bidders. Visually, there is a weak positive relationship between GPP and the number of bidders, but the scatter plot to the right indicates a weak negative relationship between GPP and the number of bids. If anything, this illustrates the importance of analyzing the effect of GPP on competition when procurement, market, contract, and potential supplier characteristics are held constant.

\section{Empirical analysis}

As shown in Sect. 3, a first step to empirically evaluate green public procurement as an environmental policy instrument is to evaluate how green criteria affect the potential suppliers' decisions to participate in the procurement process. By approximating the full set of potential suppliers for a given contract as those suppliers in the data that entered a bid within the same LMA at least once, the participation decision modeled in Eq. (3) is estimated as a logit model at the contract level with the following specification ${ }^{27}$ :

$$
y_{i j m}=\alpha_{i}+\beta_{1}^{\prime} x_{i}+\beta_{2}^{\prime} s_{j}+\beta_{3}^{\prime} z_{m}+\beta_{4} N_{j m}+\varepsilon_{i j m}
$$

where $y_{i j m}$ is a binary variable taking a value of one if potential supplier $i$ has placed a bid on contract $j$ in procurement $m$. The $\beta$ :s are the parameter vectors to be estimated, and $\varepsilon_{i j m}$ represents unobserved circumstances that affect the probability that potential supplier $i$ submits a bid.

The $x_{i}$ vector includes characteristics of the potential supplier, such as SIZE and LTD; see Table 2. If there are any economies of scale among the suppliers, the size variable will capture this. The green variables that are included in the vector of procurement characteristics, $z_{m}$, i.e., EMS, ECO, VEH, CHEM, MON, and OTHER, are defined as dummy variables. ${ }^{28}$ They are supposed to capture to what extent green criteria affect the expected profitability of potential suppliers participating in the procurement process, of which the cost of adapting to criteria is one component in the participation cost, $k_{i m}$ [Eq. (1)]. The $z_{m}$ vector also contains interaction variables that are supposed to capture whether potential suppliers of different sizes respond differently to green criteria. Also included in $z_{m}$ is a dummy variable for $M E A T$ that distinguishes procurements with only mandatory green qualification criteria (lowest price) from those with only award criteria or award criteria combined with mandatory criteria.

\footnotetext{
27 The model is estimated at the contract level because the decision about which contracts to bid on implicitly determines the participation at the procurement level.

28 All six dummy variables are included in the estimations because the green criteria they capture are not mutually exclusive.
} 
Supplier fixed effects $\left(\alpha_{i}\right)$ are included to capture heterogeneities among potential suppliers that are not captured by the variables SIZE and LTD (Jofre-Bonet and Pesendorfer 2003), e.g., differences in production technologies and processes. This means that any unobserved differences in technologies and processes related to environmental performance are controlled for. Therefore, if the coefficients for the green variables show a significant negative sign, it indicates that the green criteria are restrictive and lower the probability that potential brown suppliers will participate in the procurement process. Green potential suppliers by definition fulfill the environmental adjustments without making any adjustments. In this case, it cannot be ruled out that GPP in the form of a transformation policy has positive environmental effects. However, if there are no significant or positive significant relationships between green criteria, the probability of participation indicates that there is no cost for adapting to the criteria. In this case, the transformation policy has failed to fulfill its purpose to spur potential suppliers to make environmental investments. However, a positive relationship indicates that more of the potential suppliers that a priori fulfill the green criteria are given incentives to participate because the contracting authority signals that it values the environment and is willing to pay a price preference. That is, already green suppliers with a higher unit cost in production are attracted to a greater extent and the transformation policy has actually become a substitution policy in accordance with Marron (1997). Other variables related to supplier, contract, and procurement characteristics, as defined in the data section, are used as controls (See Table 6 in "Appendix 2").

The number of potential suppliers, $N_{j m}$, is included in Eq. (6). This number varies across procurements and potentially also across contracts. Holding everything else constant, the participation probability is expected to decrease as the number of potential suppliers increases analogously with Li and Zheng (2009).

As discussed in Sect. 3, the aggregate of all the potential suppliers' individual decisions to participate in the procurement process (and bid on one or more contract) or not is one factor that determines the possibilities for GPP working as an environmental policy instrument. The decision to submit a bid is made on the contract level because contracts in one and the same procurement are auctioned individually. It is, therefore, relevant to estimate the effect of green criteria on the number of bidders at the contract level ${ }^{29}$ :

$$
n_{j m}=\alpha_{0}+\beta_{1}^{\prime} s_{j}+\beta_{2}^{\prime} z_{m}+\beta_{3} N_{j m}+\varepsilon_{j m}
$$

Because $n_{j m}$ is a count variable, Eq. (7) is estimated using a zero-truncated negative binomial regression model. ${ }^{30}$ The included variables are motivated as described above. Note, however, that the number of bidders is expected to increase along with the number of potential suppliers. Because estimations are conducted on aggregate levels, the variables capturing the bidders' size, interaction effects, and

\footnotetext{
29 One and the same procurement might include more than one contract. They are not identical and vary in terms of area to be cleaned, geographic region, and the type of object to be cleaned. Further, the potential suppliers have the option of bidding on one or several of the contracts.

${ }^{30}$ We utilized a zero-truncated negative binomial regression model for the reasons that no bid count was zero and also because a fitted Poisson regression model showed signs of overdispersion.
} 
fixed effects are not relevant in this case. The $\varepsilon_{j m}$ term represents unobserved circumstances that affect the number of bidders and the number of bids on the contract level.

Another important aspect of including green criteria in public procurement is the qualification process. For instance, misinterpretations of green criteria by the bidders can lead to received bids being disqualified if they have not adapted to these criteria as desired by the contracting authority (see Sect. 3). Therefore, the relationship between green criteria and the probability of being qualified is estimated in a logit framework at the procurement level as follows ${ }^{31}$ :

$$
d_{i m}=\alpha_{i}+\beta_{1}^{\prime} x_{i}+\beta_{2}^{\prime} z_{m}+\beta_{3} n_{m}+\varepsilon_{i m}
$$

where $d_{i m}$ is a binary variable as previously explained [see Eq. (5)]. The included variables are motivated in the same way as in Eq. (6) except that the number of potential bidders has been replaced with the number of received bids, $n_{m}$. The $\varepsilon_{i m}$ captures unobserved differences in bidder and procurement characteristics.

\subsection{Results}

Table 3 presents the estimated coefficients of main interest from Eqs. (6) to (8), i.e., models $1-3 .^{32}$ For a full presentation of the results, see Table 6 in "Appendix 2." The overall impression is that environmental concern in public procurement regarding cleaning services in Sweden during 2009 and 2010 was not effective as an environmental policy instrument.

The one exception is the coefficient for EMS, which shows a consistent impact throughout all models in Table 3. A negative impact on suppliers' decisions on whether to participate in procurement auctions (Model 1) and on the number of bids at the contract level (Model 2) indicate that these systems are costly to implement. This result might seem logical considering that environmental certificates come with a price tag. However, an environmental management system need not be formally certified to fulfill the EMS criteria. Potential suppliers can present their systems in their own prepared documents as long as the systems are in accordance with certified equivalents. However, this might be an explanation for the significant negative effect on the probability that received bids are being qualified (Model 3). The contents of a system might be insufficient and, therefore, not meet the formal requirements for certification. Also, the supplier's self-prepared documents can be difficult to interpret by the buyer due to poor presentation. Thus, the EMS criterion potentially adds complexity and non-transparency to the procurement process.

It is difficult to draw any conclusion about the environmental impact from the EMS criterion in the procurements studied here. On the one hand, the negative impact on the participation decision is promising because it indicates that there are

\footnotetext{
31 Equation (8) is estimated at the procurement level because the screening of bidders is performed irrespective of how many contracts a bidder has placed a bid on.

${ }^{32}$ We have checked the pairwise correlations among the independent variables to see if our models suffer from multicollinearity problems and find no sign of multicollinearity, except for the interaction variables, which is expected. The correlation matrix is available from the authors upon request.
} 
Table 3 Estimation results

\begin{tabular}{|c|c|c|c|c|c|c|}
\hline \multirow[t]{3}{*}{ Variable } & \multirow{2}{*}{\multicolumn{2}{|c|}{$\frac{\text { Model } 1}{\text { Participation }}$}} & \multirow{2}{*}{\multicolumn{2}{|c|}{$\frac{\text { Model } 2}{\text { Competition }}$}} & \multirow{2}{*}{\multicolumn{2}{|c|}{$\frac{\text { Model } 3}{\text { Qualification }}$}} \\
\hline & & & & & & \\
\hline & Coef. & SE & Coef. & SE & Coef & SE \\
\hline EMS & $-0.419^{*}$ & 0.246 & $-0.254 * * *$ & 0.081 & $-1.469 * * *$ & 0.457 \\
\hline ECO & $0.457 *$ & 0.243 & -0.008 & 0.065 & -0.181 & 0.434 \\
\hline VEH & -0.048 & 0.359 & $0.329 * *$ & 0.152 & -1.491 & 2.172 \\
\hline CHEM & 0.226 & 0.234 & -0.042 & 0.066 & $-1.025^{* *}$ & 0.440 \\
\hline MON & 0.152 & 0.277 & 0.164 & 0.128 & $2.114 * *$ & 0.977 \\
\hline OTHER & 0.143 & 0.237 & -0.084 & 0.073 & -0.398 & 0.419 \\
\hline SIZE & $0.260 * *$ & 0.119 & - & - & -0.031 & 0.310 \\
\hline EMS and SIZE & 0.009 & 0.025 & - & - & $0.112 * *$ & 0.052 \\
\hline ECO and SIZE & $-0.046^{*}$ & 0.026 & - & - & 0.011 & 0.051 \\
\hline VEH and SIZE & 0.052 & 0.039 & - & - & 0.187 & 0.300 \\
\hline CHEM and SIZE & -0.032 & 0.028 & - & - & $0.113 * *$ & 0.051 \\
\hline MON and SIZE & 0.025 & 0.030 & - & - & -0.061 & 0.121 \\
\hline OTHER and SIZE & -0.023 & 0.026 & - & - & 0.018 & 0.052 \\
\hline MEAT $($ Yes $=1)$ & 0.021 & 0.087 & 0.031 & 0.067 & -0.124 & 0.177 \\
\hline$N_{j m}$ & $-0.013 * * *$ & 0.001 & $0.003 * * *$ & 0.000 & - & - \\
\hline$n_{m}$ & - & - & - & - & -0.008 & 0.020 \\
\hline Potential supplier fixed effects & Yes & & No & & Yes & \\
\hline Controls & Yes & & Yes & & Yes & \\
\hline Observations & 30,000 & & 722 & & 1,861 & \\
\hline Pseudo $R^{2}$ & 0.324 & & 0.080 & & 0.260 & \\
\hline
\end{tabular}

Note that standard errors are clustered on procurement level in Model 1 and Model 2

$* p<0.10$, ** $p<0.05$, *** $p<0.01$

potential suppliers that need to adapt to the criterion to be allowed to participate in the procurement process. Some of them, therefore, refrain from adapting because it costs too much. This is also supported by the negative impact on the number of bids at the contract level. On the other hand, environmental management systems and certificates concern the potential supplier's organization, not the actual emissions from its production process including inputs (see footnote 19). Together with the negative effect on qualification, the EMS criterion makes GPP a vague and unclear environmental policy instrument.

In contrast to the EMS criterion, the only criterion with no significant effect throughout all models is other eco demands (OTHER). However, this particular variable includes criteria that might differ considerably with respect to the environmental problems that they aim to address, and it is possible that a criterion with a significant positive effect is neutralized by other criteria with significant negative effects. 
If we look more closely at the three estimated models in Table 3, we see both significant positive and negative effects from green criteria that contribute jointly to the models. ${ }^{33}$ In Model 1, besides the negative coefficient for EMS, the coefficient for ECO indicates a significant positive effect on the potential suppliers' probability of participating in procurement processes. Eco labels are in general associated with inputs that are not directly associated with the supplier that provides the cleaning service, e.g., the content of the cleaning materials. Demanding eco labels should primarily attract potential suppliers that already use certified inputs, and this is a signal that the extra cost for having certified inputs will pay off in terms of higher expected profit from participating in the procurement process. However, while ECO criteria increased the probability of potential suppliers deciding to participate in procurement processes, this does not necessarily mean that the number of bidders at the contract level increases, as indicated by Model 2. Finally, the coefficient for the eco labeling types of criteria does not indicate any significant effect on the probability of becoming qualified in Model 3. These types of criteria are relatively easy to understand and to report and, as such, qualification should not be affected.

In Model 2, the coefficient related to VEH (e.g., Euroclass, fuel specifics and eco driving) indicates positive significant effect on the number of bids at the contract level. Again, it can be interpreted as those potential suppliers that already fulfill the criteria are attracted to a larger extent. The positive effect suggests that demanding environmental standards related to vehicles is associated with increased competition and the EU regulations regarding vehicles could be the contributing factor to this outcome. Potential suppliers with relatively new vehicle fleets find it more profitable to participate in procurements where this investment will be rewarded.

As the estimated Model 3 indicates, the screening of bids against the criterion related to chemical use and legislation (CHEM) seems problematic from the bidders' point of view. The coefficient is negative and significant, i.e., chemical demand increases the probability of bids being disqualified. This criterion seems to add complexity, and it leads to the bidders either misunderstanding the criteria or not presenting their chemical standards clearly enough for the contracting authorities. In this case, because the coefficient for the chemical criterion is insignificant in all the other models, the explanation might be that the potential suppliers do not understand this criterion and, therefore, do not realize how demanding it is. Therefore, the criterion does not make the suppliers change their behavior.

Also indicated by the estimated Model 3, and in contrast to CHEM, a significant positive coefficient for MON indicates that monitoring increases the probability of bids being qualified. A signal to potential suppliers that the contracting authority aims at monitoring the environmental quality of the service performed can be received as a sign of seriousness. Therefore, one interpretation would be that the bids are of higher quality when monitoring is one of the criteria.

In conclusion, we can say that GPP has not had any general effective impact on suppliers' behavior within the Swedish cleaning service sector.

\footnotetext{
${ }_{33}$ Wald tests for the null hypothesis that the six green criteria are jointly zero for Models 1-3 produce the $p$ values according to $0.0226,0.0220$, and 0.0025 , respectively.
} 
However, there are other aspects of interest. Table 3 shows that the larger potential suppliers are more likely to participate in procurement processes. A natural extension of the discussion is to look at the combined effect of potential suppliers' size in terms of number of employees and different green criteria, which we will do below. The fact that the regression models are non-linear complicates the interpretation of the interaction effects because they cannot be reduced to a single number (Greene 2010). The marginal effects on the dependent variable of the GPP variables vary over the support of SIZE; hence, a graphical approach is needed. See Figs. 4 and 5, respectively.

The effects of the interaction between the green variables and the SIZE variable on the potential suppliers' probability to participate in a procurement are shown in Fig. 4. For example, the top left panel of the figure illustrates the marginal effect of EMS on the probability of entry and the 95 percent confidence interval includes a zero effect on entry along the whole support of SIZE. This means that there is no firm size-specific effect on the probability of entry.

From Figs. 4 and 5 we observe that in general there are no interaction effects significantly different from zero and therefore no differences between potential suppliers of different size categories in how they respond to green criteria in the procurement process. There is, however, one exception. The middle graph in the upper part of Fig. 4 shows that the larger the size of the potential supplier, the more its probability of participating is negatively affected by the contracting authorities demanding eco labeling-this applies up to about size category 9, which corresponds to 500-999 employees. The overall impression of the effect of eco labeling as illustrated in Fig. 4 and Table 3 could indicate that eco labeling mostly attracts potential suppliers that belong to smaller size categories. The interaction effects on the probability of bids being qualified are shown in Fig. 5; essentially the reasoning for Fig. 4 applies here as well.

Finally, there are other variables presented in Table 3 that could be seen as controls but are still interesting in the context of GPP as an environmental policy instrument. Holding everything else constant, the probability of entry decreases along with the number of potential suppliers as indicated by the coefficient in Model 1. This result is in line with the prediction of Li and Zheng (2009) and is explained by the reduced probability of winning the contract in Eq. (1). The effect on the number of qualified bids at the contract level (Model 2) is positive. ${ }^{34}$ However, the statistically significant effect is small, and thus this variable has a very limited effect on the number of qualified bids.

The overall conclusion is that taking environmental concerns into account when allocating public contracts in the Swedish cleaning service sector generates little response from the suppliers. That is, they generally do not adapt to the green criteria that the contracting authorities specify in the call for tender and no significant environmental impact should be expected. One explanation is simply that the criteria are not stringent enough and, in this particular case, GPP is shown to be a

\footnotetext{
${ }^{34}$ This might seem like a paradox but it is not. The estimation of the probability of entry includes both outcomes (non-entry and entry), while the estimation of the number of bidders is the sum of individual entry decisions only.
} 

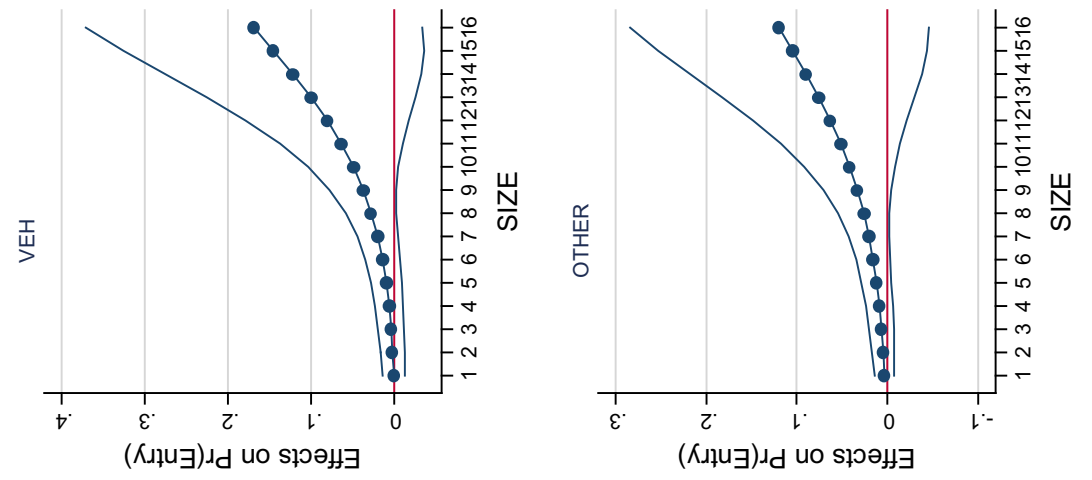

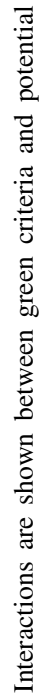
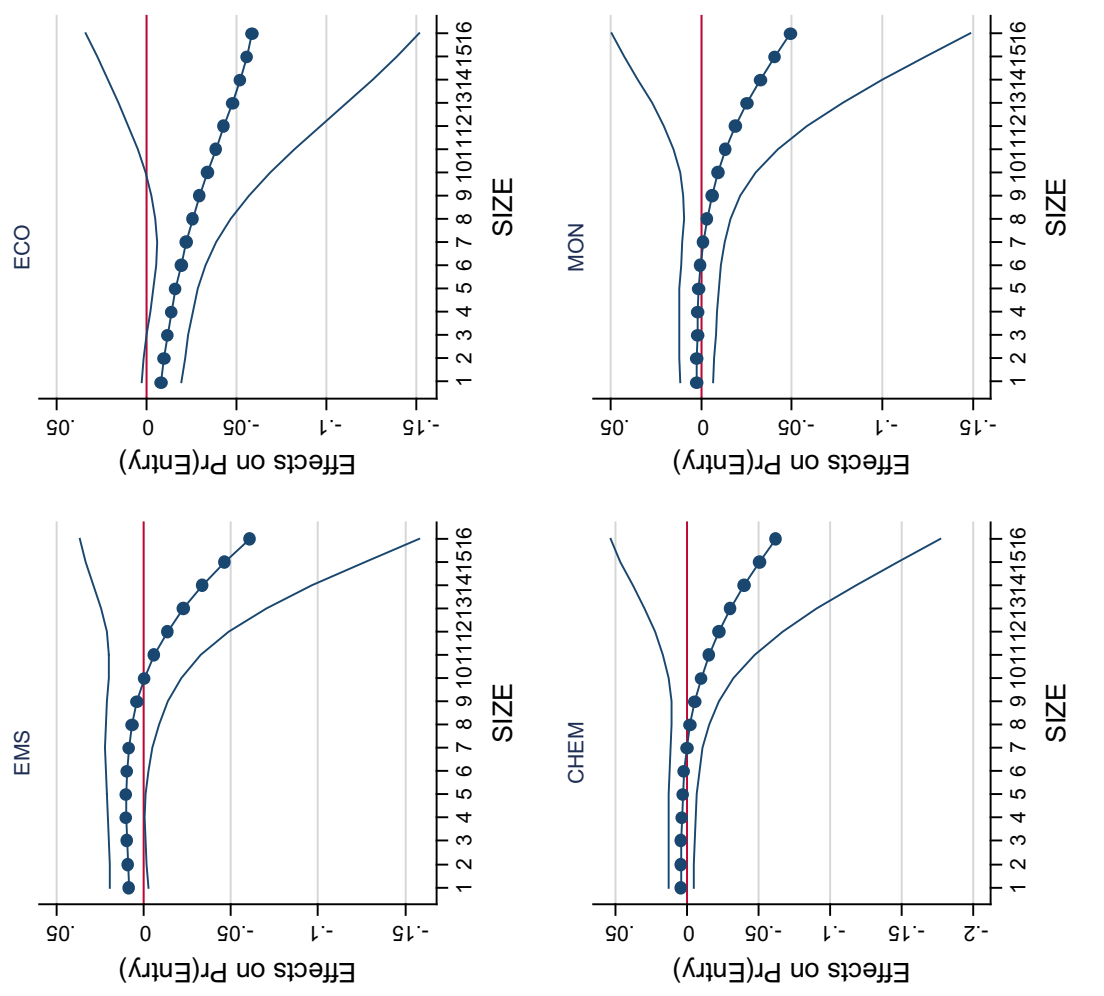

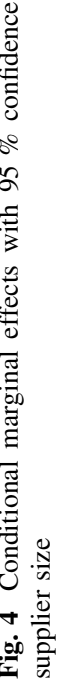



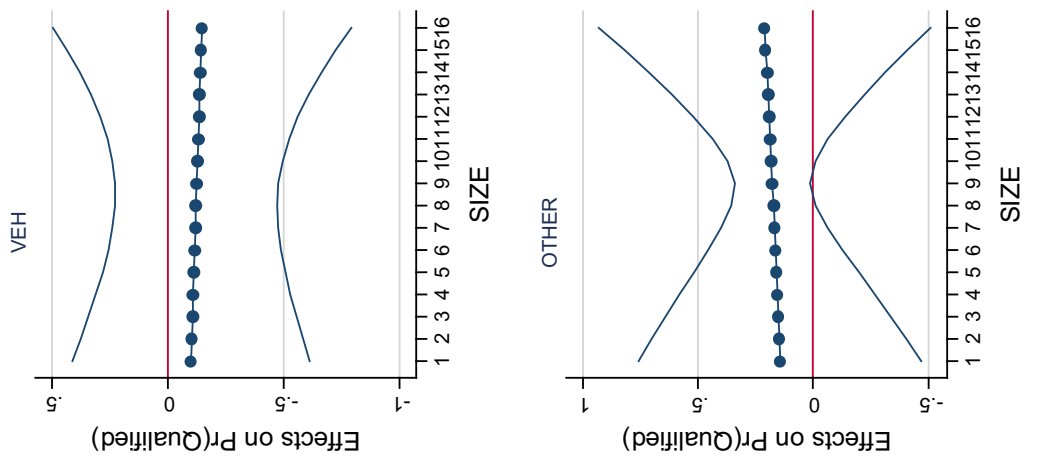

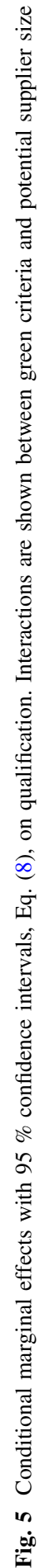
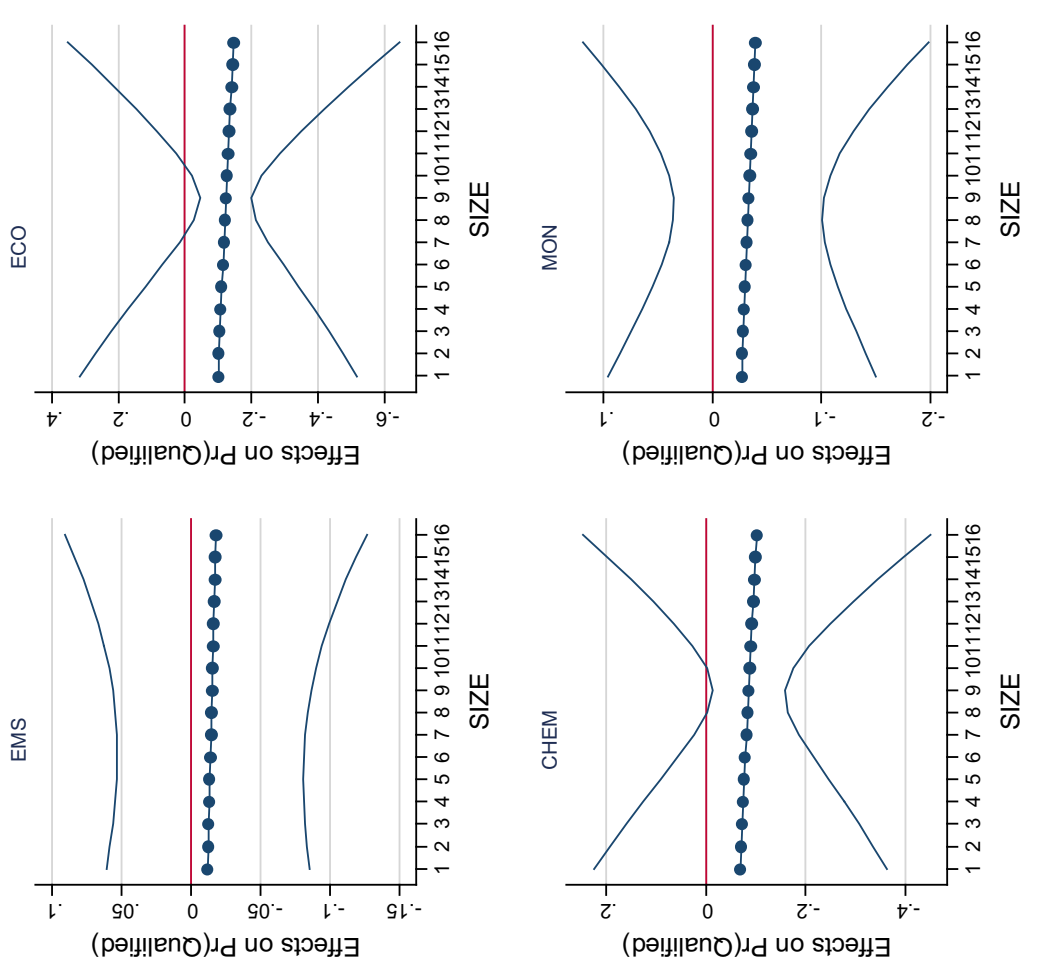
weak environmental policy instrument. Furthermore, the results show that the inclusion of green criteria adds complexity to the suppliers' bid preparation process, which is not promising from an environmental policy point of view. This complexity could have been motivated if there was evidence that the green criteria influence potential suppliers to invest in greener technologies. This is, according to our findings, not the case. A natural question is whether our results are sensitive to the measure of potential suppliers. In Appendix 3, we report estimates of the effects of GPP on entry and number of qualified bids using all distinct bidders in the data (Table 7). The results are broadly consistent across the two measures of potential suppliers.

\section{Summary and discussion}

The public sector accounts for a significant part of the economy, and by integrating environmental considerations into public procurement authorities are expected to have the power to influence private producers to behave in less environmentally damaging ways. This way of enacting environmental policies through GPP is increasingly seen by politicians as a powerful environmental policy instrument, but this lacks support in the academic literature.

If a procurement in which green criteria are stipulated only attracts already green suppliers, a counteractive effect among private consumers might arise (Marron 1997). This is due to changes in the relative prices. When the public sector chooses green instead of conventional products, price-sensitive private consumers will move in the opposite direction. A solution to this problem would be to stipulate green criteria that require potential suppliers to invest in greener technology. As recent theoretical studies have demonstrated (Lundberg and Marklund 2011, 2013a), unless suppliers with less green production choose to adapt, there will be at most a relatively small reduction in emissions. Environmental policy via the entry mechanism in public procurement is thus most likely weaker than the use of more traditional instruments.

The environmental concerns, i.e., the green criteria, can appear as mandatory qualification criteria or award criteria in which a bid with high environmental standards earns extra points in comparison to other bids.

The aim of this paper has been to empirically study environmental concern in public procurement with respect to potential suppliers' decisions to participate in the procurement process and to what extent green criteria affect the probability of qualifying for a procurement. The study was conducted on Swedish regular cleaning services data that is unique in that it contains very detailed information on the environmental standards set by the contracting authorities.

The overall conclusion is that the design of GPP, which includes different categories of green criteria, only has limited impact on the participation decision and on the aggregate number of bidders. As such, GPP appears to have limited or no potential to function as an environmental policy instrument. There is no support of systematic self-selection with respect to firm size in relation to procurements with different green criteria. The qualification process reveals that GPP is associated with 
increased complexity as indicated by the reduced probability of a bid becoming qualified when environmental management systems or regulation of chemical use is the criterion.

Additionally, an interesting observation made in our analysis is that in none of the procurements in which green criteria were specified we were able to identify what specific environmental objective the criteria sought to address. This is particularly interesting since the political ambitions to promote GPP as an environmental policy instrument are extensive. Furthermore, in only 10 percent of the procurements did the contracting authority plan to follow-up on the green criteria. In combination with our empirical results, this shows that the political ambitions for using GPP rest on shaky ground.

There is a substantial need for further empirical analysis to better understand how to use GPP to the best benefit of society. For example, from an economics point of view, weak incentives for adaption of environmentally less damaging technologies in combination with an upward effect of GPP on price would be problematic. If environmental concern in the allocation of public contracts has no or only minor contribution to environmental improvements but comes at a higher cost, at least two issues arise. First, the counteracting effect among private consumers identified in Marron (1997) might very well take effect. Second, the price increase without the intended environmental improvement would be synonymous to higher transaction costs and green washing. This is a question for future research.

Open Access This article is distributed under the terms of the Creative Commons Attribution License which permits any use, distribution, and reproduction in any medium, provided the original author(s) and the source are credited.

\section{Appendix 1}

See Tables 4 and 5. 
Table 4 Total number of criteria over all 337 procurements

\begin{tabular}{|c|c|c|c|c|c|}
\hline Environmental criteria & $\%$ & Obs. & Quality criteria & $\%$ & Obs. \\
\hline 1. Planned environmental revision & 10 & 337 & 1. Insurance & 45 & 337 \\
\hline $\begin{array}{l}\text { 2. Environmentally friendly brand, cleaning } \\
\text { products }\end{array}$ & 61 & 337 & 2. Limited liability insurance & 88 & 337 \\
\hline $\begin{array}{l}\text { 3. Swedish Environmental Management } \\
\text { Council (MSR) }\end{array}$ & 24 & 337 & 3. Credit rating & 74 & 337 \\
\hline 4. Swedish Chemicals Agency B-list & 17 & 337 & 4. Affidavit & 49 & 337 \\
\hline 5. Swedish Chemicals Agency O-list & 6 & 337 & $\begin{array}{l}\text { 5. Documentation from the Tax } \\
\text { Authority }\end{array}$ & 58 & 337 \\
\hline $\begin{array}{l}\text { 6. Swedish Work Environment Authority } \\
\text { Chemicals }\end{array}$ & 3 & 337 & 6. Annual report & 32 & 337 \\
\hline 7. The Swedish Environmental Code & 21 & 337 & 7. Information on turnover & 19 & 337 \\
\hline 8. REACH & 1 & 337 & $\begin{array}{l}\text { 8. The firm has to provide a } \\
\text { bank deposit }\end{array}$ & 1 & 337 \\
\hline $\begin{array}{l}\text { 9. Code of Statutes of the Swedish Chemicals } \\
\text { Agency } 2008^{\mathrm{a}}\end{array}$ & 4 & 337 & 9. Experience required & 85 & 337 \\
\hline $\begin{array}{l}\text { 10. Code of Statutes of the Swedish } \\
\text { Chemicals Agency } 1994^{\mathrm{b}}\end{array}$ & 1 & 337 & $\begin{array}{l}\text { 10. Provision of list of all earlier } \\
\text { jobs }\end{array}$ & 4 & 337 \\
\hline 11. Routines for bookkeeping of chemicals & 42 & 337 & 11. References required & 84 & 337 \\
\hline $\begin{array}{l}\text { 12. Provision of list of intended use of } \\
\text { chemicals }\end{array}$ & 21 & 337 & 12. Original references required & 11 & 337 \\
\hline 13. Continuously updated list of chemicals & 5 & 337 & $\begin{array}{l}\text { 13. Foreman needs a cleaning } \\
\text { certificate }\end{array}$ & 50 & 337 \\
\hline 14. Environmental criteria, vehicles & 3 & 337 & $\begin{array}{l}\text { 14. Foreman needs equivalent } \\
\text { of a cleaning certificate }\end{array}$ & 11 & 337 \\
\hline 15. Environmental criteria, fuel & 1 & 337 & $\begin{array}{l}\text { 15. Foreman's } \mathrm{CV} \text { needs to be } \\
\text { provided }\end{array}$ & 42 & 337 \\
\hline 16. Eco driving & 1 & 337 & $\begin{array}{l}\text { 16. Swedish-speaking } \\
\text { employees }\end{array}$ & 67 & 337 \\
\hline 17. Plan for decreasing need for fossil fuel & 2 & 337 & $\begin{array}{l}\text { 17. Criminal records must be } \\
\text { provided }\end{array}$ & 23 & 337 \\
\hline 18. Allergy-friendly cleaning products & 31 & 337 & $\begin{array}{l}\text { 18. The firm must be connected } \\
\text { to a union }\end{array}$ & 6 & 337 \\
\hline $\begin{array}{l}\text { 19. Swedish Chemicals Agency Code of } \\
\text { Statutes } 2005\end{array}$ & 8 & 337 & $\begin{array}{l}\text { 19. Firm must act as equivalent } \\
\text { to union terms }\end{array}$ & 28 & 337 \\
\hline $\begin{array}{l}\text { 20. Non-allergenic substances as defined by } \\
\text { IFRA-norm }\end{array}$ & 6 & 337 & $\begin{array}{l}\text { 20. Plan of how to structure } \\
\text { work }\end{array}$ & 60 & 337 \\
\hline $\begin{array}{l}\text { 21. Firm required to have an environmental } \\
\text { management system }\end{array}$ & 60 & 337 & 21. Firm needs a quality plan & 77 & 337 \\
\hline $\begin{array}{l}\text { 22. Firm required to have a documented } \\
\text { environmental management system }\end{array}$ & 51 & 337 & $\begin{array}{l}\text { 22. Firm needs a certified } \\
\text { quality plan }\end{array}$ & 37 & 337 \\
\hline $\begin{array}{l}\text { 23. Firm required to have an environmental } \\
\text { certificate }\end{array}$ & 30 & 337 & 23. Insta 800 & 14 & 337 \\
\hline 24. ISO standard 14000 & 13 & 337 & 24. SIS & 21 & 337 \\
\hline 25. ISO standard 14001 & 24 & 337 & 25. ISO standard 9000 & 22 & 337 \\
\hline 26. ISO standard 14024 & 1 & 337 & 26. Quality follow-up required & 84 & 337 \\
\hline
\end{tabular}


Table 4 continued

\begin{tabular}{|c|c|c|c|c|c|}
\hline Environmental criteria & $\%$ & Obs. & Quality criteria & $\%$ & Obs. \\
\hline 27. ISO standard 14025 & 1 & 337 & & & \\
\hline 28. EU eco classification of vehicles & 1 & 337 & & & \\
\hline
\end{tabular}

a The Swedish Chemicals Agency's Chemical Products and Biotechnical Organisms Regulations (KIFS 2008:2)

b Older version of KIFS 2008:2

Table 5 Definition of firm size according to SCB's definition and class size frequency in data

\begin{tabular}{llc}
\hline Class size $(S I Z E)$ & Number of employees & Frequency \\
\hline 1. & 0 & 31 \\
2. & $1-4$ & 54 \\
3. & $5-9$ & 30 \\
4. & $10-19$ & 34 \\
5. & $20-49$ & 52 \\
6. & $50-99$ & 35 \\
7. & $100-199$ & 24 \\
8. & $200-499$ & 18 \\
9. & $500-999$ & 4 \\
10. & $1,000-1,499$ & 3 \\
11. & $1,500-1,999$ & 0 \\
12. & $2,000-2,999$ & 2 \\
13. & $3,000-3,999$ & 3 \\
14. & $4,000-4,999$ & 1 \\
15. & $5,000-9,999$ & 8 \\
16. & $10,000-$ & 2 \\
Observations & & 301 \\
\hline
\end{tabular}

\section{Appendix 2}

See Table 6. 
Table 6 Full version of Table 3

\begin{tabular}{|c|c|c|c|c|c|c|}
\hline & \multicolumn{2}{|c|}{$\begin{array}{l}\text { Model } 1 \\
\text { Participation }\end{array}$} & \multicolumn{2}{|l|}{$\begin{array}{l}\text { Model } 2 \\
\text { Competition }\end{array}$} & \multicolumn{2}{|l|}{$\begin{array}{l}\text { Model } 3 \\
\text { Qualification }\end{array}$} \\
\hline & Coef. & SE & Coef. & SE & Coef. & SE \\
\hline EMS & $-0.419 *$ & 0.246 & $-0.254 * * *$ & 0.081 & $-1.469 * * *$ & 0.457 \\
\hline ECO & $0.457 *$ & 0.243 & -0.008 & 0.065 & -0.181 & 0.434 \\
\hline VEH & -0.048 & 0.359 & $0.329 * *$ & 0.152 & -1.491 & 2.172 \\
\hline CHEM & 0.226 & 0.234 & -0.042 & 0.066 & $-1.025 * *$ & 0.440 \\
\hline MON & 0.152 & 0.277 & 0.164 & 0.128 & $2.114^{* *}$ & 0.977 \\
\hline OTHER & 0.143 & 0.237 & -0.084 & 0.073 & -0.398 & 0.419 \\
\hline SIZE & $0.260 * *$ & 0.119 & - & - & -0.031 & 0.310 \\
\hline EMS and SIZE & 0.009 & 0.025 & - & - & $0.112^{* * *}$ & 0.052 \\
\hline ECO and SIZE & $-0.046^{*}$ & 0.026 & - & - & 0.011 & 0.051 \\
\hline VEH and SIZE & 0.052 & 0.039 & - & - & 0.187 & 0.300 \\
\hline CHEM and SIZE & -0.032 & 0.028 & - & - & $0.113^{* *}$ & 0.051 \\
\hline MON and SIZE & 0.025 & 0.030 & - & - & -0.061 & 0.121 \\
\hline OTHER and SIZE & -0.023 & 0.026 & - & - & 0.018 & 0.052 \\
\hline MEAT $($ Yes $=1)$ & 0.021 & 0.087 & 0.031 & 0.067 & -0.124 & 0.177 \\
\hline \#SUBC & $-0.008 *$ & 0.004 & $0.005 *$ & 0.003 & $0.087 * * *$ & 0.028 \\
\hline ln (\#SQMC) & $0.078 * * *$ & 0.030 & $0.077 * * *$ & 0.022 & - & \\
\hline MUNI (Yes = 1) & 0.067 & 0.104 & 0.088 & 0.077 & -0.248 & 0.194 \\
\hline FIN & 0.145 & 0.278 & -0.007 & 0.170 & 0.008 & 0.845 \\
\hline INS & -0.120 & 0.130 & $-0.185^{*}$ & 0.107 & -0.132 & 0.298 \\
\hline EXP & $-0.266^{*}$ & 0.161 & -0.128 & 0.093 & $-1.068 * *$ & 0.436 \\
\hline PER & $-0.718^{*}$ & 0.434 & -0.125 & 0.180 & $1.414 * * *$ & 0.543 \\
\hline $\mathrm{SOC}$ & -0.042 & 0.092 & 0.010 & 0.074 & 0.146 & 0.200 \\
\hline STAF & $0.338 *$ & 0.202 & 0.198 & 0.121 & -0.659 & 0.438 \\
\hline SCHOOL $($ Yes $=1)$ & -0.023 & 0.094 & -0.006 & 0.068 & - & - \\
\hline OFFICE $($ Yes = 1) & 0.056 & 0.099 & 0.005 & 0.071 & - & - \\
\hline OTHER $($ Yes $=1)$ & $-0.225^{* *}$ & 0.088 & $-0.172 * *$ & 0.070 & - & - \\
\hline SERVICE & $-0.111 * * *$ & 0.035 & $-0.071 * * *$ & 0.025 & 0.019 & 0.075 \\
\hline$N_{j m}$ & $-0.013^{* * *}$ & 0.001 & $0.003 * * *$ & 0.000 & - & \\
\hline $\operatorname{LTD}($ Yes $=1)$ & 1.957 & 1.346 & - & & 3.538 & 2.535 \\
\hline $\operatorname{HEADQ}(\mathrm{Yes}=1)$ & $1.228 * * *$ & 0.116 & - & & 0.309 & 0.259 \\
\hline ln (\#SQMP) & - & & - & & $-0.232 * * *$ & 0.075 \\
\hline$n_{j m}$ & - & & - & & -0.008 & 0.020 \\
\hline Potential supplier fixed effects & Yes & & No & & Yes & \\
\hline Constant & $-4.300 * * *$ & 1.231 & $1.405 * * *$ & 0.305 & 3.033 & 2.116 \\
\hline lnalpha & & & $-3.506 * * *$ & 0.630 & & \\
\hline Observations & 30,000 & & 722 & & 1,861 & \\
\hline Pseudo $R^{2}$ & 0.324 & & 0.080 & & 0.260 & \\
\hline
\end{tabular}

Note that standard errors are clustered on procurement level in Model 1 and Model 2

$* p<0.10, * * p<0.05, * * * p<0.01$ 


\section{Appendix 3: Robustness analysis of entry and number of qualified bidders}

The empirical model of entry (Model 1) requires that we have a measure of potential suppliers $\left(N_{j m}\right)$ for each contract. In the main analysis, we use the labor market area (LMA) as the relevant area of commerce resulting in approximately 14 potential suppliers per region on average. So, if a supplier submits a bid in a procurement in a given LMA at least once during the sample period, it is defined as a potential supplier in all procurements taking place in that particular region. Defining the set of potential suppliers is challenging because the supplier might be interested in contracts outside the geographical region, which is why we perform a robustness check, as follows.We extend the set of potential suppliers to cover all suppliers observed at least once in the sample. This measure results in $N_{j m}=341$ potential suppliers.

As shown in Table 7, the results for the wider definition of potential suppliers are broadly consistent with the findings in the main analysis. The estimated coefficient on EMS is still negative but becomes statistically insignificant. Further, the estimated coefficient on vehicles VEH does not alter the sign but becomes statistically significant. That being said, this definition of potential suppliers could be too wide and include potential suppliers that primarily are interested in contracts in its nearest geographical area which motivates the use of the alternative definition.

When it comes to the regression specification for the number of qualified bidders (Model 2), all six estimated coefficients now become statistically insignificant. Note, however, that the variable $N_{j m}$ is invariant and drops out of the regression. We argue that it is reasonable to control for potential suppliers when fitting a model to the number of qualified bids. 
Table 7 Determinants of entry and number of qualified bidders with full set of potential suppliers

\begin{tabular}{|c|c|c|c|c|}
\hline & \multicolumn{2}{|c|}{$\begin{array}{l}\text { Model } 1 \\
\text { Participation }\end{array}$} & \multicolumn{2}{|l|}{$\begin{array}{l}\text { Model } 2 \\
\text { Competition }\end{array}$} \\
\hline & Coef. & SE & Coef. & SE \\
\hline EMS & -0.057 & 0.278 & -0.093 & 0.080 \\
\hline $\mathrm{ECO}$ & $0.621 * *$ & 0.292 & 0.108 & 0.066 \\
\hline VEH & $-0.794 * *$ & 0.370 & 0.077 & 0.166 \\
\hline CHEM & 0.318 & 0.283 & -0.069 & 0.073 \\
\hline MON & -0.082 & 0.268 & 0.109 & 0.153 \\
\hline OTHER & -0.057 & 0.286 & -0.066 & 0.075 \\
\hline SIZE & $0.260 *$ & 0.144 & - & - \\
\hline EMS \& SIZE & $-0.063 *$ & 0.036 & - & - \\
\hline ECO \& SIZE & $-0.091 * *$ & 0.038 & - & - \\
\hline VEH \& SIZE & $0.166 * * *$ & 0.050 & - & - \\
\hline CHEM \& SIZE & -0.028 & 0.040 & - & - \\
\hline MON \& SIZE & 0.044 & 0.038 & - & - \\
\hline OTHER \& SIZE & -0.007 & 0.039 & - & - \\
\hline $\operatorname{MEAT}($ Yes $=1)$ & -0.050 & 0.088 & 0.074 & 0.072 \\
\hline \#SUBC & 0.001 & 0.004 & $0.006^{*}$ & 0.003 \\
\hline $\ln (\# S Q M C)$ & $0.055^{*}$ & 0.031 & $0.091 * * *$ & 0.025 \\
\hline MUNI (Yes = 1) & 0.111 & 0.119 & 0.127 & 0.081 \\
\hline FIN & 0.203 & 0.329 & 0.023 & 0.175 \\
\hline INS & -0.213 & 0.171 & $-0.232^{* *}$ & 0.113 \\
\hline EXP & 0.022 & 0.183 & -0.225 & 0.139 \\
\hline PER & -0.518 & 0.382 & -0.169 & 0.248 \\
\hline SOC & 0.064 & 0.097 & 0.020 & 0.080 \\
\hline STAF & 0.126 & 0.189 & $0.350 * * *$ & 0.123 \\
\hline SCHOOL $($ Yes $=1)$ & -0.026 & 0.096 & -0.031 & 0.072 \\
\hline OFFICE $($ Yes $=1)$ & 0.140 & 0.102 & -0.004 & 0.077 \\
\hline OTHER $($ Yes = 1) & -0.108 & 0.082 & $-0.211^{* * *}$ & 0.071 \\
\hline SERVICE & 0.022 & 0.037 & $-0.096^{* * *}$ & 0.029 \\
\hline LTD $($ Yes = 1) & $4.454 * * *$ & 1.423 & - & - \\
\hline HEADQ $($ Yes = 1) & $2.880 * * *$ & 0.142 & - & - \\
\hline Potential supplier fixed effects & Yes & & No & \\
\hline Constant & $-8.983 * * *$ & 1.293 & $1.442 * * *$ & 0.375 \\
\hline lnalpha & & & $-2.577 * * *$ & 0.337 \\
\hline Observations & 180,090 & & 722 & \\
\hline Pseudo $R^{2}$ & 0.410 & & 0.039 & \\
\hline
\end{tabular}

Note that standard errors are clustered on procurement level in Model 1 and Model 2

$* p<0.10, * * p<0.05, * * * p<0.01$ 


\section{References}

Arvidsson A, Stage J (2012) Technology-neutral green procurement in practice: an example from Swedish waste management. Waste Manage Res 30:519-523

Asker J, Cantillon E (2008) Properties of scoring auctions. RAND J Econ 39:69-85

Asker J, Cantillon E (2010) Procurement when price and quality matter. RAND J Econ 41:1-34

Bergman MA, Lundberg S (2013) Tender Evaluation and Supplier Selection Methods in Public Procurement. J Purch Supply Manage 19:73-83

Bolton P (2008) Protecting the environment through public procurement: the case of South Africa. Nat Resour Forum 32:1-10

Che Y-K (1993) Design competition through multidimensional auction. RAND J Econ 24:668-680

Dini F, Pacini R, Valletti T (2006) Scoring Rules. In: Nicola D, Piga G, Spagnolo G (eds) Handbook of Procurement. Cambridge University Press, Cambridge, pp 293-321

Directive 2004/17/EC of the European Parliament and of the Council of 31 March 2004 coordinating the procurement procedures of entities operating in the water, energy, transport and postal services sectors $(30.04 .2004)$

Directive 2004/18/EC of the European Parliament and of the Council of 31 March 2004 on the coordination of procedures for the award of public works contracts, public supply contracts and public service contracts (30.04.2004)

European Commission (2011) Buying green! A handbook on green public procurement, 2nd edn. Publications Office of the European Union, Luxembourg

European Commission (2008) Communication from the Commission to the European Parliament, the Council, the European Economic and Social Committee and the Committee of the Regions on the sustainable consumption and production and sustainable industrial policy action plan. COM (2008) 397/3, Brussels

Fischer EA (2010) Green procurement: overview and issues for congress. CRS report for congress, Congressional Research Service

Geng Y, Doberstein B (2008) Greening government procurement in developing countries: building capacity in China. J Environ Manage 88:932-938

Greene W (2010) Testing hypotheses about interaction terms in nonlinear models. Econ Lett 107:291-296

Heyes A (2009) Is Environmental Regulation Bad for Competition? A Survey. J Regul Econ 36:1-28

Ho LWP, Dickinson NM, Chan GYS (2010) Green procurement in the asian public sector and the Hong Kong private sector. Nat Resour Forum 34:24-38

http://ec.europa.eu/internal_market/publicprocurement/rules/current/index_en.htm. Accessed 27 June 2014

http://ec.europa.eu/environment/air/transport/road.htm. Accessed 27 June 2014

http://ec.europa.eu/enterprise/sectors/chemicals/reach/index_en.htm. Accessed 27 June 2014

http://ec.europa.eu/environment/gpp/versus_en.htm. Accessed 24 Nov 2014

http://ec.europa.eu/environment/gpp/gpp_criteria_en.htm. Accessed 24 Nov 2014

http://www.iso.org/iso/iso14000. Accessed June $27^{\text {th }} 2014$

http://www.kemi.se/. Accessed 27 June 2014

Jofre-Bonet M, Pesendorfer M (2000) Bidding behavior in a repeated procurement auction: a summary. Euro Econ Rev 44:1006-1020

Jofre-Bonet M, Pesendorfer M (2003) Estimation of a dynamic auction game. Econometrica 71:1443-1489

Krasnokutskaya E, Seim K (2011) Bid preference programs and participation in highway procurement auctions. Am Econ Rev 101:2653-2686

Latacz-Lohmann U, Van der Hamsvoorth C (1997) Auctioning conservation contracts: a theoretical analysis and an application. Am J Agric Econ 79:407-418

Levin D, Smith JL (1994) Equilibrium in auctions with entry. Am Econ Rev 84:585-599

Li L, Geiser K (2005) Environmentally responsible public procurement (ERRP) and its implications for integrated product policy (IPP). J Clean Prod 13:705-715

Li T, Zheng X (2009) Entry and competition effects in first-price auctions: theory and evidence form procurement auctions. Rev Econ Studies 76:1397-1429

Lundberg S, Marklund P-O (2011) The pivotal nature of award methods in green public procurement. Environ Econ 2:64-73 
Lundberg S, Marklund P-O (2013a) Green Public Procurement as an Environmental Policy Instrument: Cost Effectiveness. Environmental Economics 4:75-83

Lundberg S, Marklund P-O (2013b) Offentlig Upphandling eller Gröna Nedköp? En ESO Rapport om Miljöpolitiska Ambitioner. Report to Expertgruppen för studier i offentlig ekonomi 2013:13. In Swedish with English summary

Lundberg S, Marklund P-O, Strömbäck E (2012) Objective Effectiveness of Green Public Procurement. IPPC, the 5th International Public Procurement Conference, 17-19 August, Seattle. IPPA: International Public Procurement Association, pp 1145-1174

Marron DB (1997) Buying green: government procurement as an instrument of environmental policy. Public Financ Rev 25:285-305

McFadden D (1974) Conditional Logit Analysis of Qualitative Choice Behavior. In: Zarembka Paul (ed) Frontiers in Econometrics. Academic Press, New York, pp 105-142

Milgrom P (2004) Putting auction theory to work. Cambridge University Press, Cambridge

Palmujoki A, Parikka-Alhola K, Ekroos A (2010) Green public procurement: analysis of the use of environmental criteria in contracts. Rev Euro Comm Int Law 19:250-255

Parikka-Alhola K (2008) Promoting environmentally sound furniture by green public procurement. Ecol Econ 68:472-485

Samuelson WF (1985) Competitive bidding with entry costs. Econ Lett 17:53-57

Stoneham G, Chaudhri V, Strappazzon L (2003) Auctions for conservation contracts: an empirical examination of Victoria's bush tender trial. Aust J Agric Resour Econ 47:477-500

Swanson M, Weissman A, Davis G, Socolof ML, Davis K (2005) Developing priorities for greener state government purchasing: a California case study. J Clean Prod 13:669-677

Tarantini M, Dominici Loprieno A, Porta PL (2011) A life cycle approach to green public procurement of building material and elements: a case study of windows. Energy 36:2473-3482

Testa F, Iraldo F, Frey M, Daddi T (2012) What factors influence the uptake of GPP (green public procurement) practices? New evidence from an Italian survey. Ecol Econ 82:88-96

Tukker A, Emmert S, Charter M, Vezzoli M, Sto E, Andersen MM, Geerken T, Tischner U, Lahlou S (2008) Fostering change to sustainable consumption and production: an evidence based view. J Clean Prod 16:1218-1225

Walker H, Brammer S (2009) Sustainable procurement in the United Kingdom public sector. Supply Chain Manage Int J 14:128-137

Wan Z, Beil DR (2009) RFQ auctions with supplier qualification screening. Oper Res 57:934-949 